\title{
WELDING OF ALUMINUM METAL MATRIX COMPOSITES (AL/SiC-MMCs)
}

\author{
A. I. Selmy*, M. M. Ghanem **, K. A. Abd El-Azem*** \\ * Department of Mechanical Design and Production Engineering Dept., \\ Faculty of Engineering, Zagazig University, Egypt \\ **.Welding Technology Department, Central Metallurgical $R \& D \cdot I n s t i t u t e ~(C M R D I)$, \\ P.O.Box 87 Helwan,Egypt, ghanem105@yahoo.com \\ *** QA/QC Department, Petroleum Projects Company (PETROJET)
}

\begin{abstract}
Due to their high specific-strength, $\mathrm{SiC}$ reinforced aluminum metal matrix composites (Al/SiC$\mathrm{MMCs}$ ) are becoming popular for wide range of applications including vehicles, aircraft, rockets and shipbuilding. It is difficult to fusion weld such material due to porosity and aluminum carbide (A14C3) formation in weld zone (WZ) which result in degradation of mechanical properties of the welded joints. In this study, several sets of Al/SiC-MMCs samples having 0, 5, 15 and 20 vol.\% $\mathrm{SiC}$ particulates were fabricated by powder metallurgy technique using hot compaction of $\mathrm{Al}$ and $\mathrm{SiC}$ powders followed by hot extrusion. Effect of welding conditions such as heat input, filler wire type (AA4043 and non-commercial AlTi5B1) and without filler using AC-GTAW (TIG) process was studied to find out appropriate conditions to get sound welded joints. Microstructure was examined using optical and SEM. Phases were identified and analyzed using XRD and EDX analysis. It was found that porosity and $\mathrm{AL}_{4} \mathrm{C}_{3}$ formed in $\mathrm{WZ}$ during welding without filler and with AA4043 filler. Using non-commercial AlTi5B1 filler, porosity and $\mathrm{Al}_{4} \mathrm{C}_{3}$ were reduced and suppressed at $20 \mathrm{vol} \% \mathrm{SiC}$ and $5.86 \mathrm{Kj} / \mathrm{cm}$ heat input. Whereas, hardness values in $\mathrm{WZ}$ remain as high as base metal when using non-commercial AITi5B1 filler, but drastically reduced when welding without and with AA4043 filler. The new filler wire of AlTi5B1, was examined for the first time and proved as promising filler in welding A1/SiC-MMC.

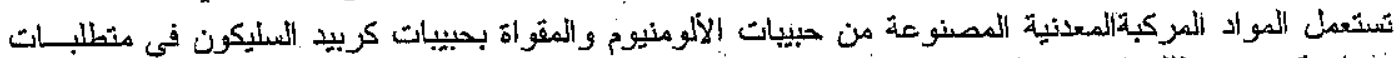

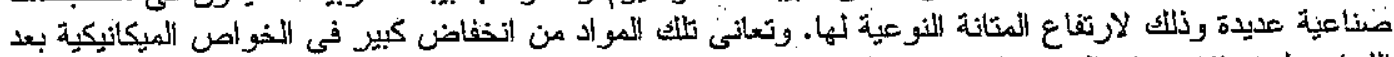

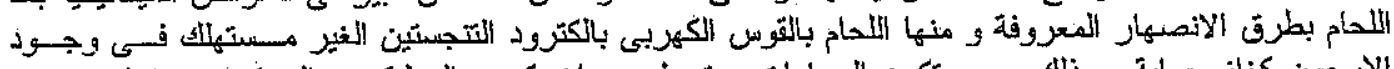

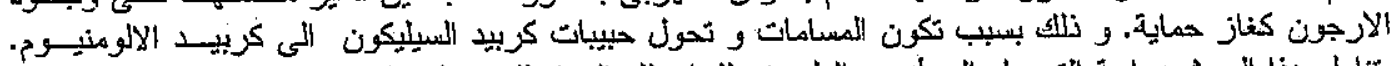

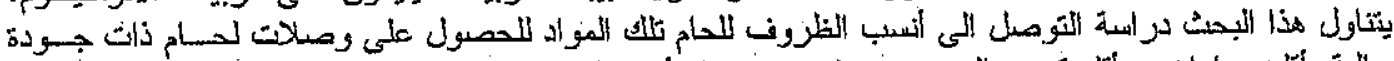

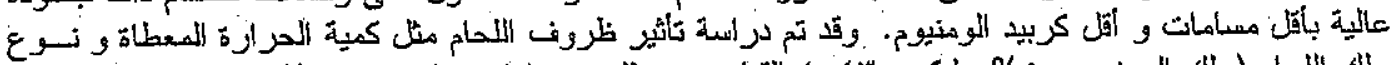

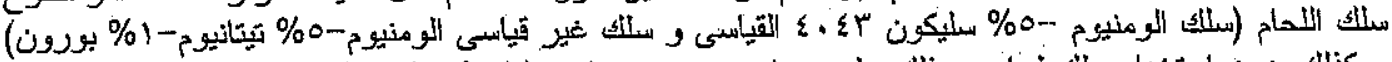

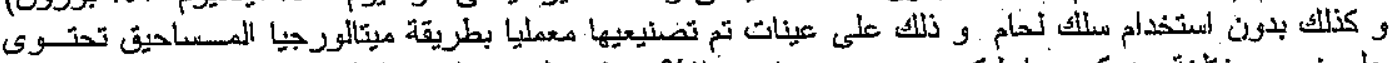

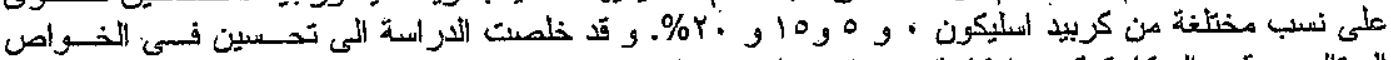

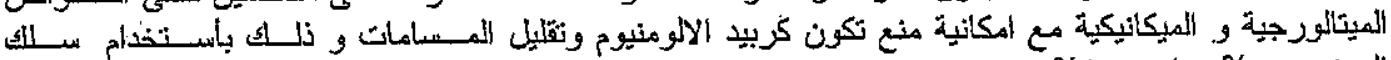

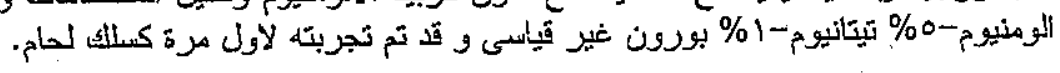

Keywords: Metal Matrix Composites, Al/SiC, GTAW, Filler wire, Hardness, Heat input.

\section{INTRODUCTION}

At present, there is a great interest in the application of metal matrix composites (MMCs). Potential uses of these materials are numerous, in industries such as aerospace, defense, sports goods, and marine structures. When compared with the un-reinforced matrix alloys, MMCs have superior properties, especially increased stiffness, high strength, good wear resistance, and excellent elevated temperature properties can be tailored to satisfy a number of requirements. Despite the potential advantages of using MMCs, at present they have not reached widespread industrial application. There are several reasons for the limited use of MMCs. The major one being that their production costs are significantly higher than traditional alloys and that joining is not a trivial matter. In the latter regard, fabrication of virtually any complex structure requires joining to be made. The disparate nature of most matrixes and 
reinforcement materials greatly affects the ease with which welding can be performed. Reflecting the various material development studies carried out; there is an emphasis on Al-based materials. Where metal matrix composites (MMCs) are becoming more popular as structural materials, and joining them is, therefore of a paramount importance [1]. Concerning fusion welding of $\mathrm{MMC}$, a number of difficulties have been identified specifically, in particular:

1. High viscosity of $\mathrm{MMC}$ melts above the melting point when compared with un-reinforced melts.

2. Segregation effects on re-solidification.

3. Reinforcement-matrix interactions.

4. Evolution of gases.

During fusion welding, the matrix will be heated to a temperature above its melting point, but the particular will remain solid. In sequence, particle reinforced Al-alloys have melts with high viscosities, making the mixing of the molten parent melt metal and filler difficult to a chive [2]. This can, however be alleviated by employing Si-rich Al-filler wires such as AA4043 or AA4047 and may be less marked when welding MMC based on Si-rich matrixes. The use of Si-rich Al-filler increases the wetability of $\mathrm{SiC}$ in an Al matrix enhancing mixing of the plate and filler materials [2]. Nevertheless, the rejection of $\mathrm{SiC}$ during solidification tends to give un-reinforced regions of particulate-free $\mathrm{Al}$ alloy. For $\mathrm{Al} 203$ reinforced $\mathrm{Al} M \mathrm{MMC}$, the use of high $\mathrm{Mg}$ containing wires (ER5356) is preferable, preventing the $\mathrm{Al}_{2} \mathrm{O}_{3}$ from dewetting and "clumping" [2]. In principle, fluidity of the weld pool might be increased by increasing its temperature, but this can load to further problems because of detrimental reactions between reinforcement and matrix materials. The reaction between $\mathrm{Al}$ \& $\mathrm{SiC}$ in $\mathrm{SiC}$ reinforced $\mathrm{Al}$ MMC during welding and casting has been well-documented $[3,4]$ and occurs as follows;

$$
3 \mathrm{SiC}+4 \mathrm{Al} \longrightarrow \mathrm{Al}_{4} \mathrm{C}_{3}+3 \mathrm{Si}
$$

The $\mathrm{Al}_{4} \mathrm{C}_{3}$ is detrimental to the properties of the weld for two reasons. First, the platelets are brittle, reducing fracture toughness, and second, the weld corrodes due to moisture attack of the $\mathrm{Al}_{4} \mathrm{C}_{3}$ to give acetylene, resulting in a weld life expectancy in the atmosphere of only days [4-6].

Therefore, the objective of this work is to investigate effect of welding conditions such as heat input, filler wire type (AA 4043 and the new non-commercial AlTi5B 1) and without using filler on porosity and $\mathrm{Al}_{4} \mathrm{C}_{3}$ formation in order to fiend out appropriate welding conditions to get sound welded joints using AC-GTAW process.

\section{EXPERIMENTAL WORK}

$\mathrm{Al} / \mathrm{SiC} \mathrm{MMCs}$ produced form aluminum pon with size less than $80 \mu \mathrm{m}$ and $\mathrm{SiC}$ powder with : less than $30 \mu \mathrm{m}$. AV/SiC MMCs with different volut fractions of $\mathrm{SiC} 0,5,15 \& 20$ vol.\% samples wer fabricated by hot compaction and hot extrusion using powder metallurgy technique. Hot compaction is the step in which the blended pure powders ( $\mathrm{Al} \& \mathrm{SiC}$ ) heated and pressed into primarily shape using press that are hydraulically activated. The hot compaction process was made in order to produce prefabricated samples with $35 \mathrm{~mm} \phi$ and height 50 to $60 \mathrm{~mm}$ according to the amount of powder filling. The hot pressing process is the step where the pressure applied to the hot powder at a temperature of 530 $550^{\circ} \mathrm{C}$. Hydraulic press unite with maximum pressing capacity of 75 tons, the selected pressure was $420 \mathrm{MPa}$ which is higher than the pressure required for aluminum $(70-275) \mathrm{MPa}$ [7]. The pressing process for the powder continued for $7 \mathrm{~min}$. the samples were extruded at $500^{\circ} \mathrm{C}$ with extrusion ratio of $8: 1$ to the required shape (rectangular shape with $300 \times 30 \times 4 \mathrm{~mm})$. The physical properties and Vickers hardness measurements of the produced composites were determined.

Prior to welding, samples were cleaned using acetone to remove oils and then mechanically cleaned using stainless steels wire brush to remove surface oxides. Bead on plate welding was performed using $\mathrm{AC}$ GTAW (TIG) process with pure tungsten electrode having $2.4 \mathrm{~mm} \square$, arc length $2.4 \mathrm{~mm}$ and argon flow rate $10 \mathrm{lit} / \mathrm{min}$. Heat input used ranged from 5.4 to $7.75 \mathrm{kj} / \mathrm{cm}$ Heat input calculated using the equation:

$$
\text { heat input }=60\left(\mathrm{E}^{*} \mathrm{I} / \mathrm{S}\right) \quad(\mathrm{Joule} / \mathrm{cm})
$$

Where: I: welding current (amp), E: arc voltage (volt), S: welding speed ( $\mathrm{cm} / \mathrm{min})$, Welding was done autogenously and with two different filler wires, standard AA4043 (2.4mm D) and nonstandard new wire AlTi5B1 (2.0mm $\square$ ). Welding conditions are given in Table 1 . Cross-section samples were cut from both base metals and the welded joints at specific weld locations, for examination using optical and scanning electron microscope (SEM) The sections were prepared by polishing and etching with a modified Keller's reagent consisting of $85 \mathrm{ml}$ distilled water, $3 \mathrm{ml}$ $\mathrm{HF}, 3 \mathrm{ml} \mathrm{HCl}$ and $1.5 \mathrm{ml} \mathrm{HNO}$. Specimens immersed for $5 \mathrm{sec}$, and then water washed and blows dry. Phases identified using X-ray diffraction (XRD) and analyzed using SEM equipped with energy dispersive $\mathrm{X}$-ray analyzer (EDX). Hardness measured using Vickers hardness (Hv) machine operated at $10 \mathrm{~kg}$ load. 
Table 1 Welding conditions used in this study

\begin{tabular}{|c|c|c|c|c|c|}
\hline $\begin{array}{c}\text { Specimen } \\
\text { No. }\end{array}$ & $\begin{array}{c}\text { A } \\
\text { (anp) }\end{array}$ & $\begin{array}{c}V \\
\text { (volt) }\end{array}$ & $\begin{array}{c}\text { Heai } \text { I/P } \\
(\mathrm{kj} / \mathrm{cm})\end{array}$ & SiC\% & Filler \\
\hline 1 & 150 & 15.4 & 6.93 & 5 & \\
\hline 2 & 170 & 15.2 & 7.75 & 5 & - \\
\hline 3 & 170 & 15.2 & 7.75 & 5 & - \\
\hline 4 & 170 & 15.2 & 7.75 & 15 & - \\
\hline 5 & 135 & 16 & 6.78 & 5 & - \\
\hline 6 & 115 & 17 & 5.86 & 20 & - \\
\hline 7 & 135 & 16 & 6.48 & 15 & - \\
\hline 8 & 115 & 19 & 6.55 & 5 & AA4043 \\
\hline 9 & 115 & 19 & 6.55 & 15 & AA4043 \\
\hline 10 & 115 & 17 & 5.86 & 20 & AA4043 \\
\hline 11 & 135 & 17 & 6.88 & 5 & AA4043 \\
\hline 12 & 135 & 17 & 6.88 & 15 & AA4043 \\
\hline 13 & 135 & 17 & 6.88 & 20 & AA4043 \\
\hline 14 & 135 & 17 & 6.88 & 5 & AlTi5B1 \\
\hline 15 & 135 & 17 & 6.88 & 15 & AlTi5B1 \\
\hline 16 & 135 & 17 & 6.88 & 20 & AlTi5B1 \\
\hline 17 & 115 & 17 & 5.86 & 5 & AlTi5B1 \\
\hline 18 & 115 & 17 & 5.86 & 15 & AlTi5B1 \\
\hline 19 & 115 & 17 & 5.86 & 20 & AlTi5B1 \\
\hline 20 & 90 & 20 & 5.4 & 5 & AlTi5B1 \\
\hline 21 & 90 & 20 & 5.4 & 15 & AiTi5B1 \\
\hline 22 & 90 & 20 & 5.4 & 20 & AlTi5B1 \\
\hline
\end{tabular}

Table 2 deviation from theoretical density

\begin{tabular}{|c|c|c|c|c|}
\hline SiC, vol.\% & 0 & 5 & 15 & 20 \\
\hline $\begin{array}{c}\text { The deviation from } \\
\text { theoretical deusity } \\
(\mathrm{kg} / \mathrm{m} 3)\end{array}$ & -0.001 & -0.028 & -0.061 & -0.071 \\
\hline
\end{tabular}

\section{RESULTS AND DISCUSSION}

Results of deviation between theoretical and experimental densities of the fabricated $\mathrm{Al} / \mathrm{SiC}$ MMCs base metal with $0,5,15$ and 20 vol.\% SiC are given in Table 2 . It is obvious that the void content and porosity decreased as $\mathrm{SiC}$ vol. \% decreased.

\subsection{Microstructure Investigation}

\subsubsection{Base metals}

Microstructure of the as-fabricated AI/SiC-MMC with $20 \mathrm{SiC}$ vol. $\%$ is shown in Fig. 1 This microstructure show that, $\mathrm{SiC}$ particles uniformly distributed within the aluminum matrix. Aluminum matrix and $\mathrm{SiC}$ particles have been Cleary labeled in fig. 1 , the dark regions are voids and porosity as shown in microstructure.

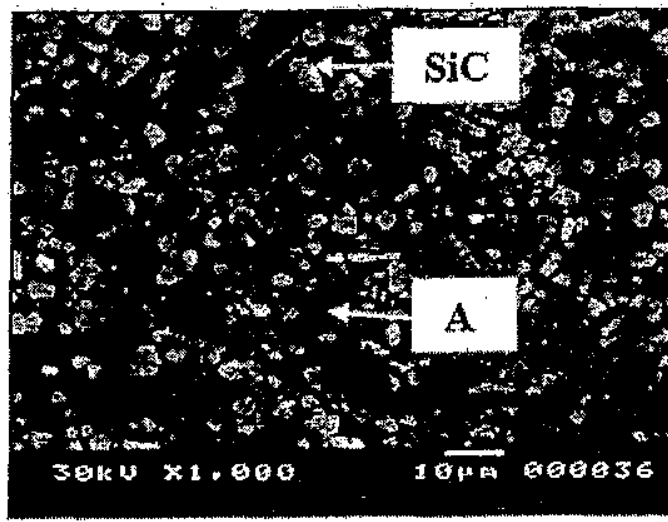

Fig. 1 Microstructure of AL/SiC-MMC, containing $20 \% \mathrm{SiC}$.

\subsubsection{Autogenous welding (without filler)}

Optical micrograph of autogenously welded specimen reveals existence of porosity in weld zone, Fig. 2. It is to be noted that porosity was formed in weld zone at the range of heat input used (5.86 7.75 $\mathrm{kj} / \mathrm{cm}$ ). At both low and high heat input porosity was high, but at intermediate heat input $(6.93 \mathrm{kj} / \mathrm{cm})$ it was the lowest. The increase in porosity content at low heat input attributed to high solidification rate of the weld pool, therefore there is no opportunity for escaping the pores. At high heat input the increase in porosity in weld zone could be attributed to the vigorous agitation and turbulence effect of the arc, thus it allow air to react with molten metal.

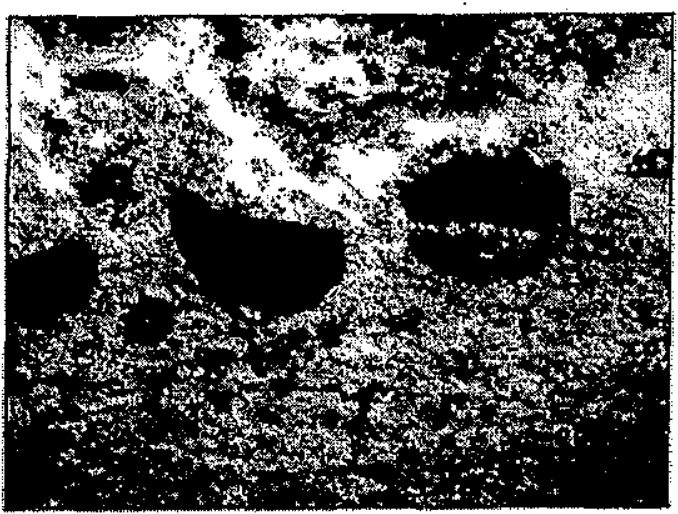

Fig. 2 Microstructure at weld zone for specimen No. 1 , containing $5 \% \mathrm{SiC}$ autogenously welded.

\subsubsection{Welding with filler wires}

Optical micrographs of welded joints using AA4043 and AlTi5B1 wires are shown in Figs. 3-5. Porosity was formed in joints welded using AA4043 filler, Fig. 3, as similar to autogenously welded joints, Fig. 2. It is obvious that porosity increased with using AA4043 filler wire compared with welding without filler. Using AlTisB1 wire as filler resulted in reducing porosity in weld zone (Fig. 4) and it nearly eliminated porosity at high $\mathrm{SiC}$ content, Fig. 5 . Porosity is formed due to hydrogen existed in 
aluminum matrix. The aluminum powder raw material is easily oxidized and it reacts with moisture to form hydrated aluminum oxide (Al2O3.3H2O). When filler melts it reacts with Al-base matrix in weld zone, resulting in breaking the bond between $\mathrm{Al}_{2} \mathrm{O}_{3}$ and $\mathrm{H} 2 \mathrm{O}$, then hydrogen evolved [9], with TiAl alloy filler, stable molten pool is gained with improving its fluidity $[10]$, resulting in hydrogen easily escaping from weld deposit.

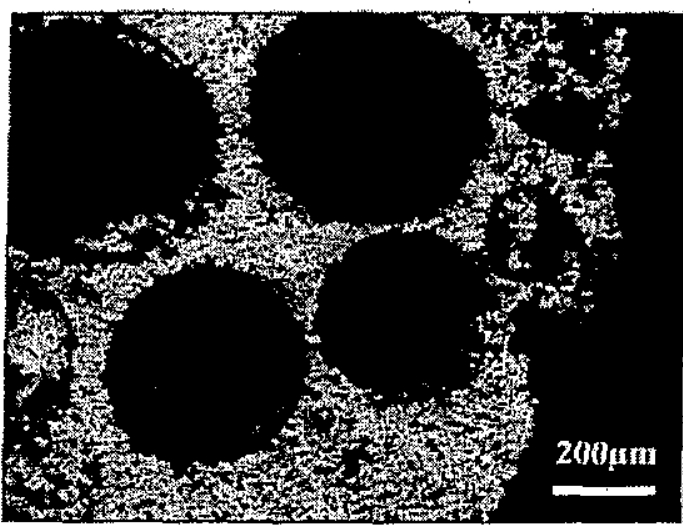

Fig. 3 Microstructure at WZ for specimen No. 8, containing 5\% SiC welded using AA4043 filler.

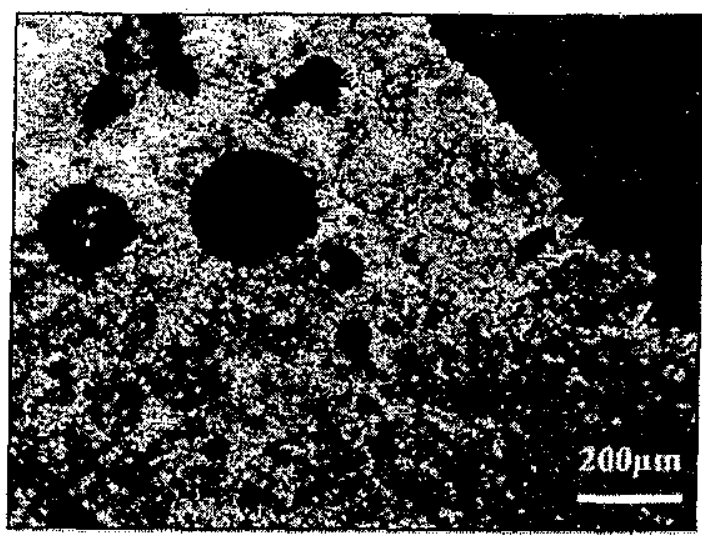

Fig. 4 Microstructure at WZ for specimen No. 18 containing $15 \%$ SiC welded using AlTi5B1.

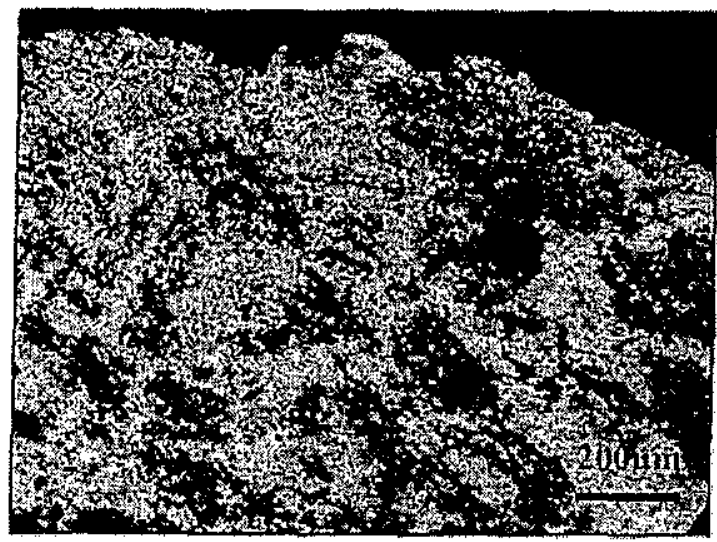

Fig. 5 Microstructure at WZ for specimen No.19 containing $20 \%$ SiC welded using AlTisB1.
SEM Micrograph at WZ of specimen contains $20 \%$ $\mathrm{SiC}$ welded autogenously is shown in Fig. 6 . It is obvious that microstructure consists of lamellar $\mathrm{Al}_{4} \mathrm{C}_{3}$ phase and aggregates of $\mathrm{Si}$ formed in $\mathrm{Al}$ matrix. SEM micrographs in weld zone of $\mathrm{Al} / 20 \% \mathrm{SiC}$ welded with $\mathrm{AA} 4043$ and the new filler AlTi5B1 are shown in Figs $7 \& 8$, respectively. It can be clearly seen that both lamellar $\mathrm{Al}_{4} \mathrm{C}_{3}$ and $\mathrm{Si}$ aggregates are formed when using AA4043 filler. However, their volume fraction is higher than that formed in the same specimen welded without filler, Fig. 6. Microstructure in $\mathrm{WZ}$ of $\mathrm{Al} / 20 \% \mathrm{SiC}$ base metal welded with AITi5B1 reveals in existence of $\mathrm{SiC}, \mathrm{TiC}, \mathrm{Al}_{3} \mathrm{Ti}$ and $\mathrm{TiO}_{2}$. These phases were identified using XRD analysis, Fig.9.It is evident that welding of AI/SiC- MMCs either autogenously or using AA4043 filler, reaction between Al \& SiC occurs resulting in formation of the detrimental $\mathrm{Al}_{4} \mathrm{C}_{3}$ and $\mathrm{Si}$ aggregates. This results in $\mathrm{SiC}$ particulate-free zones formation. When using the non-standard AlTi5B1 filler wire to weld $\mathrm{Al} / \mathrm{SiC}$ MMCs, chemical reactions occurred in WZ resulting in formation of $\mathrm{TiC}$ and the intermetallics $\mathrm{Al}_{3} \mathrm{Ti}$ in addition.

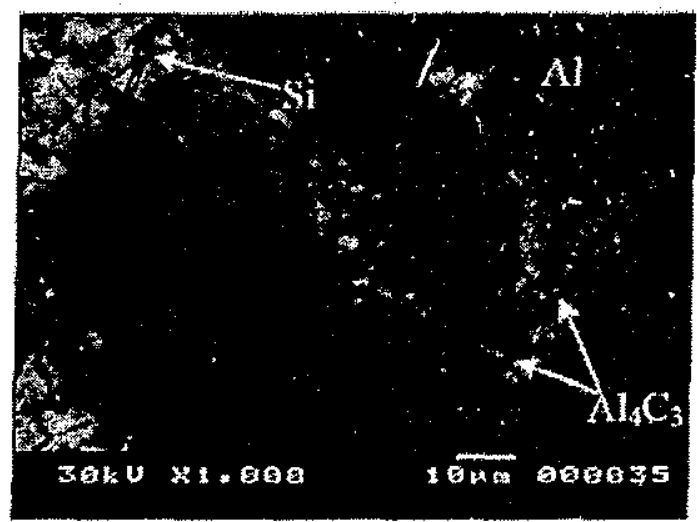

Fig.6 SEM micrograph at WZ of autogenously Weld spec. No. 6 having $20 \% \mathrm{SiC}$.

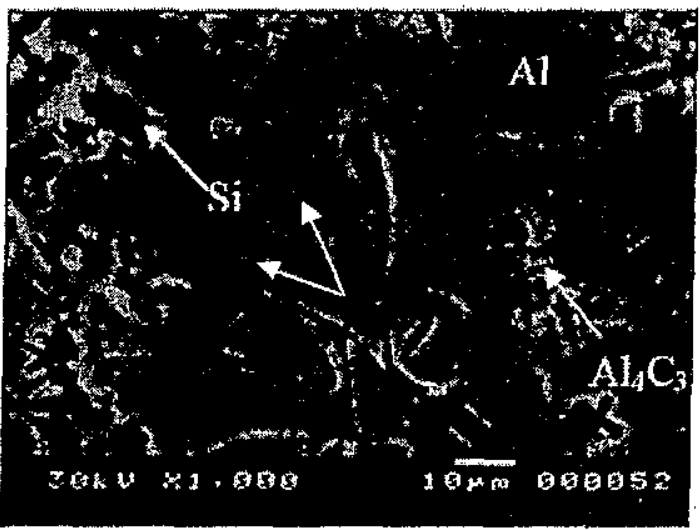

Fig 7 SEM microgr $a$ ph at WZ of $20 \%$ SiC spec. No. 10 welded with AA4043. 
Since, Ti has higher affinity than $A 1$ to react with $\mathrm{C}$ to form TiC and so suppresses the formation of the detrimental $\mathrm{Al}_{4} \mathrm{C}_{3}$ phase. Formation of $\mathrm{TiO}_{2}$ in $\mathrm{WZ}$, Fig.8 synchronized with the nearly elimination of porosity from WZ (Fig.5) when using the new AlTi5B1 filler. Based on the results of XRD analysis. and microstructure evolution, the reactions occur in weld zone; resulting in hydrogen escaping, thus nearly eliminate porosity.

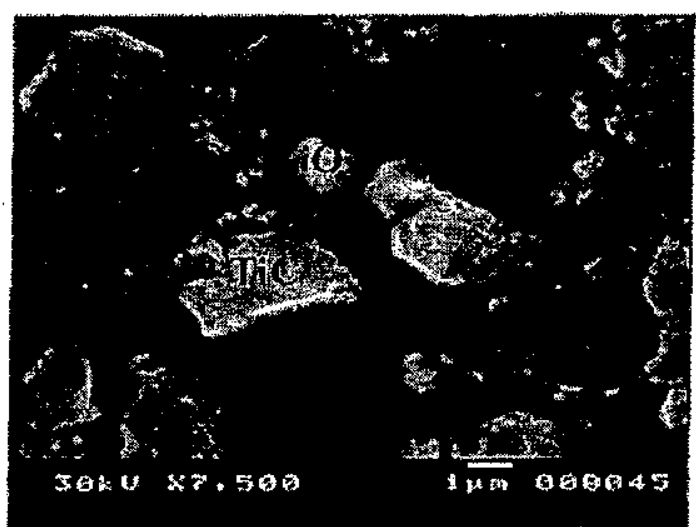

Fig. 8 SEM micrograph at WZ for spec.No.19 containing $20 \% \mathrm{SiC}$ welded using AlTi5B1.

\subsection{Hardness Measurement}

Results of hardness of Al/SiC MMCs contain 0, 5, 15 and $20 \% \mathrm{SiC}$ reinforced particles clarify increasing hardness of base metal with increasing vol.\% of the $\mathrm{SiC}$ reinforced particles, Table 3 . Results of hardness measurements of BM, HAZ and WZ of Al/SIC-MMCs containing $20 \% \mathrm{SiC}$ welded without and with AA4043 and AlTi5B1 filler are given in Table 4. While, drastic decrease in hardness values in $\mathrm{WZ}$ when welding without filler $(22 \mathrm{Hv})$ or using AA4043 filler ( $30 \mathrm{Hv}$ ), it remain unchanged when using the new AlTi5B1 filler (53Hv). These results are in good agreement with microstructure
Fig. 8 and XRD analysis Fig. 9. Using the new AlTi5B1 wire as filler in welding $\mathrm{A} / \mathrm{SiC}-\mathrm{MMC}$ is beneficial due to formation of $\mathrm{TiC}, \mathrm{Al}_{3} \mathrm{Ti}$ reinforced phases as well as eliminating formation of the determinately $\mathrm{AL}_{4} \mathrm{C}_{3}$ phase and reducing porosity in welded joints. The $\mathrm{Al}_{3} \mathrm{Ti}$ intermetallics phase formed in weld zone posses high specific strength, high specific modulus, and excellent properties both at ambient and elevated temperatures [10-15]. As compared to most other aluminum-rich intermetallics, Al3Ti is very attractive because it has a higher melting point $(\sim 1623 \mathrm{~K})$ and relatively low density $\left(3.4 \mathrm{~g} / \mathrm{cm}^{3}\right)$. Furthermore, $T i$ has low diffusivity and solubility in aluminum; hence, $\mathrm{Al}_{3} \mathrm{Ti}$ formed in weld zone can be expected to exhibit a low coarsening rate at elevated temperature. In addition, the Young's modulus of $\mathrm{Al}_{3} \mathrm{Ti}$ phase has been determined to be $216 \mathrm{GPa}$ [13]. Therefore, the presence of $\mathrm{Al}_{3} \mathrm{Ti}$ phase is very effective in increasing the stiffness of welded joints.

Table 3 Results of measured average hardness of fabricated $\mathrm{Al} / \mathrm{SiC} \mathrm{MMCs}$ at different $\mathrm{SiC} . \%$

\begin{tabular}{|c|c|c|c|c|}
\hline Specimen $\mathrm{SiC} \%$ & 0 & 5 & 15 & 20 \\
\hline Average hardiness (HV) & 29 & 43 & 49 & 55 \\
\hline
\end{tabular}

Table 4: average hardness (HV) of welded joints at base metal (BM), heat-affected zone (HAZ) and weld zone (WZ )of Al/SiC-MMC having $20 \% \mathrm{SiC}$

\begin{tabular}{|c|c|c|c|}
\hline Specimen No. & Avernge Hardnoss Vickers (HV) \\
\cline { 2 - 4 } & $\mathrm{BM}$ & $\mathrm{HAZ}$ & $\mathrm{WZ}$ \\
\hline 6 & 50 & 45 & 22 \\
\hline 10 & 57 & 34 & 30 \\
\hline 19 & 53 & 51 & 52 \\
\hline
\end{tabular}

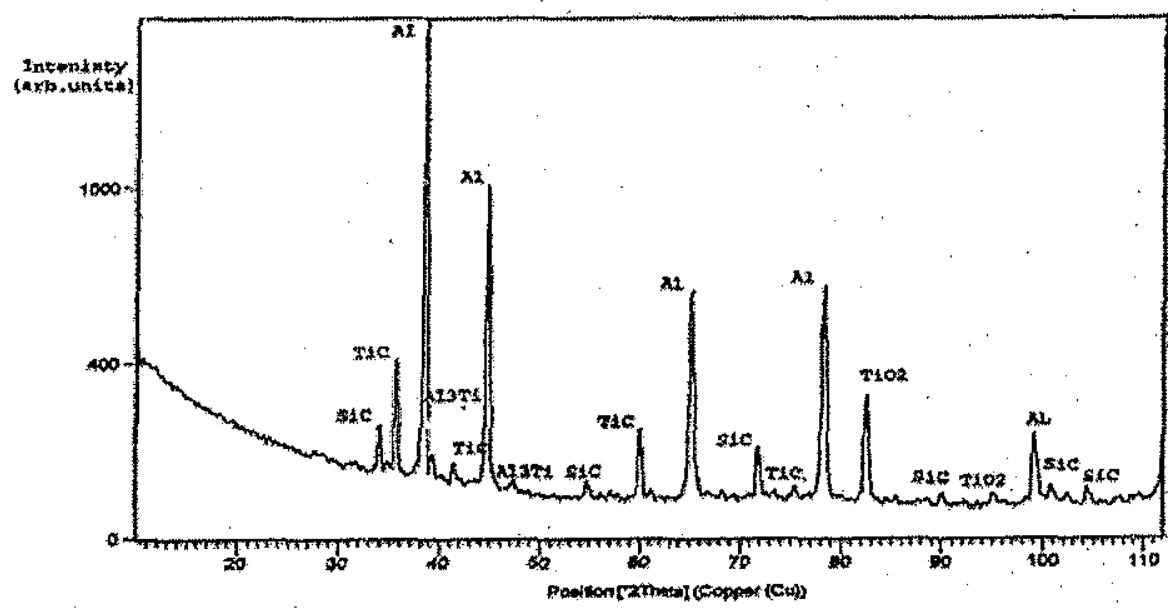

Fig. $9 \mathrm{X}$-ray diffraction pattern (XRD) at $\mathrm{WZ}$ of $\mathrm{Al} / 20 \% \mathrm{SiC} M M C$ specime No.19 welded using the new AITi5B1 filler. 


\section{CONCLUSIONS}

Based on the results of this study the following concilusions are submitted:

1- New filler wire of AlTi5B1, was examined and proved promising filler in welding $\mathrm{Al} / \mathrm{SiC}-\mathrm{MMC}$ using TIG process.

2- Using the new AlTi5B1 filler resulted in nearly eliminating porosity and suppresses the formation of the detrimental $\mathrm{Al}_{4} \mathrm{C}_{3}$ phase in weld joint comparing with autogenously welding or using the conventional AA4043 filler.

3- Whereas; drastic loss in hardness at WZ of autogenously or welding using AA4043 filler, it remain as high as base metal with using the new AITi5B1 wire.

4- The AlTi5B1 filler enhanced hardness of welded joints due to formation of $\mathrm{TiC}, \mathrm{Al} 3 \mathrm{Ti}$ and $\mathrm{TiO} 2$ reinforcing phases.

\section{REFRENCES}

[1] Ellis M B D, "Joining of aluminum based metal matrix composites", International Material Reviews, Vol.41, No.2, pp. 41-57, (1996).

[2] San Diego, C A, Duralcan Composites,"arc welding guidelins", Duralcan USA., (1991).

[3] Lloyed D J and Chamberlain B, "in cast reinforced metal composites", (ed. Fishman S G and Dhingra A K ), Metals Park, OH, pp.263269, (1988).

[4] Skiko M, Morris P L and Lloyd D J, in "cast reinforced Metal composites", (ed. Fishman S G and A K, Dhingra A K, Metals Park, OH, ASM Internaional), pp. 257-261, (1988) .

[5] Ellis M B D, Gittos M F, and Threadgill P L, "Joining of aluminum based metal matrix composites", initial studies, Members report 501, TWI, Abington, (1994).
[6] Paola B, Edoardo C, and Daniele C, "Effect of process parameters on bead properties of A359/SiC MMCs welded by laser", Composites, Part A, 38, Issue 4, pp. 1089-1098, (2007).

[7] Urena A, Gomez J M, Escaler $M D$ and Fernandet M J, "Brazeability of aluminum alloys (6xxx \& $7 \mathrm{xxx})$ series reinforced with alumina particles depends both on matrix composition and reinforcement proportion" Welding Res. pp. 92102, Feb. (1997).

[8] JIS Welding Handbook ,Jpn. Standard Snc., 1127, 1985

[9] Gen Mathers, the welding aluminum and its alloys, Woodhead Publishing Limited, Cambridge England, 2000.

[10] Yu-cheng Lei, Zhen Zhang, Jia-jun Nie, Xizhang Chen, "Effect of Ti-Al on microstructures and mechanical properties of plasma arc in-situ welded joint of SiCp/Al MMCs" Transactions of Nonferrous Metals Society of China, VoI, 18, Issue 4, pp. 809-813, (August 2008).

[11] Frazier W E, Koczak M J, In: Kim YW et al., editors, "Dispersion strengthened aluminum alloys", Warrendale (PA), TMS, p. 573, (1988).

[12] Sanjay K T, Manoj G, "Improving mechanical performance of $\mathrm{Al}$ by using $\mathrm{Ti}$ as reinforcement Composites", part A 38; pp.1010-1018, (2007).

[13] Hsu C J, Chang CY, Kao P W, Ho N J, "AlAl3Ti nanocomposites produced in situ by friction stir processing " Chang, Acta Materials 54 , pp. 5241-5249, (2006).

[14] Ramos A S, Calinas R, Viera MT, "The formation of $\gamma$-TiAl from Ti/Al multilayers with different periods", surface and coating technology, 200, pp. 6196-6200, (2006).

[15] Yu-cheng Lei, Wei-jin Yuan, Xi-zhang Chen, Fei Zhu, Xiac-nong Cheng, Transactions of Nonferrous Metals Society of China, Vol. 17, Issue 2, pp.313-317, (2007). 